\title{
RELAÇÕES PÚBLICAS E DITADURA MILITAR: IMPLICAÇÕES E IMPRESSÕES
}

DAIANE SCHEID

Universidade Federal de Santa Maria - Frederico Westphalen

Frederico Westphalen, Rio Grande do Sul, Brasil

E-mail: daiane.scheid@ufsm.com.br

TAÍLA LOPES QUADROS

Universidade de Caxias do Sul

Rio Grande do Sul, Brasil

E-mail: tailalq@hotmail.com 
Resumo: A possível influência do regime ditatorial no Brasil sobre a atividade de Relações Públicas constitui o foco do presente artigo, o qual consiste no relato de uma pesquisa exploratóriadesenvolvida sobre a profissão de relações públicas nas décadas de 60 e 70 e as relações entre esse período histórico e a profissão. Por fim, indicam-se algumas hipóteses sobre as implicações da ditadura para a profissão de Relações Públicas.

Palavras-chave: Relações Públicas; história; ditadura militar brasileira; atuação profissional.

\title{
RELACIONES PÚBLICAS Y DICTADURA MILITAR: IMPLICACIONES E IMPRESIONES
}

Resumen: La posible influencia del régimen dictatorial de Brasil sobre la actividad de Relaciones Públicas es el foco de este artículo, que es el informe de una investigación llevada a cabo en la profesión de las relaciones públicas en las décadas del 60 y 70 y la relación entre este período histórico y profesión. Finalmente, indicamos algunas hipótesis sobre las consecuencias de la dictadura a la profesión de las relaciones públicas.

Palabras clave: Relaciones Públicas; historia; dictadura militar brasileña, el rendimiento profesional.

\section{PUBLIC RELATIONS AND MILITARY DICTATORSHIP: IMPLICATIONS} AND IMPRESSIONS

\begin{abstract}
The possible influence of the dictatorial regime in Brazil on the activity of Public Relations is the focus of this article, which is the report of a research carried out on the public relations profession in the decades of 60 and 70 and the relationship between this historical period and profession. Finally, we indicate some hypotheses about the implications of the dictatorship to the profession of public relations.
\end{abstract}

Keywords: Public Relations; history; brazilian military dictatorship; professional performance. 


\section{INTRODUÇÃO}

A profissão de Relações Públicas possui diversas interfaces com o campo político. Uma das relações mais marcantes da profissão de Relações Públicas com a política brasileira foi na ditadura militar, período no qual a profissão surgia e iniciava seu desenvolvimento. Onde estavam os profissionais de Relações Públicas nesse período? Houve alguma contribuição para a sociedade por parte dos Relações Públicas? De que forma atuavam junto ao governo? Esses são alguns questionamentos que fomentam o interesse na temática e na construção deste texto.

Este artigo apresenta os resultados de uma pesquisa, desenvolvida na forma de monografia'. Caracterizada como estudo exploratório (MARCONI E LAKATOS, 1985; OLIVEIRA, 2002), inspirado em técnicas como análise historiográfica (VERGARA, 2005; ALVARENGA E ROSA, 1999), análise documental (MARCONI E LAKATOS, 1985) e entrevista fechada (DUARTE, 2005), a investigação objetivou levantar hipóteses sobre de que forma a ditadura militar do Brasil interferiu na profissão de Relações Públicas no início de sua regulamentação e as afetações disso hoje.

Para tanto,o texto inicia com uma breve contextualização sobre a ditadura, em seguida retrata a profissão de relações públicas nas décadas de 60 e 70 e finaliza aoversar a respeito das implicações entre esse período histórico e a profissão.

\section{O CONTEXTO HISTÓRICO: DITADURA MILITAR}

Para compreender as implicações de um período sobre uma área de trabalho é necessário conhecer este contexto histórico e os fatos que ocorreram simultaneamente ao desenvolvimento das Relações Públicas no Brasil. Nesse sentido, são apresentados a seguir alguns aspectos importantesdo contexto histórico da regulamentação da profissão, algumas situações que marcaram os anos do regime militar no Brasil.

No que se refere ao aspecto político, destaca-se que em meados de 1960 instaurou-se o regime ditatorial no Brasil. O golpe deu-se em 31 de março de 1964, quando o então presidente do Brasil, João Goulart (Jango) teve seu

1 Trabalho premiado no $30^{\circ}$ Concurso Universitário de Monografias e Projetos Experimentais deRelações Públicas/2012 da ABRP/SP, categoria Estudos do Campo da Comunicação Organizacional e Relações Públicas - $1^{\circ}$ lugar. 
mandato derrubado por um golpe civil e militar, justificado pelo subdesenvolvimento e atraso na industrialização do país. Os militares assumiram o poder, representados por Artur da Costa e Silva, tenente-brigadeiro. Movimentos e lideranças populares foram caçados e considerados clandestinos, diversos políticos tiveram seus mandatos cessados e direitos políticos suprimidos e o Congresso Nacional passou apenas a carimbar decretos e leis determinados pelo Executivo. Começam a ser instituídos Atos Institucionais com as novas resoluções do governo ao longo de todo o período da ditadura. Esses são alguns dados apontados por Couto (2003) que resumem o contexto na época.

Para Barros (1998) a criação dos Atos Institucionais definiu a principal característica do golpe de 31 de março, a crescente militarização do Estado no Brasil. Os novos donos da realidade explicitavam o mando absoluto através do máximo de violência e do uso indiscriminado de força. O mais rígido foi o Ato número cinco,de 1968, que estabelece inclusive a censura da imprensa e consolida de vez o autoritarismo da ditadura militar. Ao contrário dos atos anteriores, o Al-5 não tinha prazo de vigência.

Seus doze artigos permitiam o fechamento indiscriminado do Congresso Nacional, as assembleias estaduais e as câmaras municipais; reabria as cassações de direitos políticos, dessa vez por tempo indeterminado; abolia o habeas corpus para os detidos por infração da Lei de Segurança Nacional; permitia a demissão de qualquer funcionário público federal, estadual e municipal, inclusive juízes; suspendia garantias concedidas pelo poder Judiciário; permitia o confisco de bens como punição pelo que o governo considerasse corrupção (BARROS, 1998, p.42).

Toda a sociedade, principalmente a imprensa e os artistas, deveriam se submeter ao controle absoluto do governo. As instituições civis não puderam manifestar nenhuma crítica ao comportamento das autoridades. Barros (1998) relata também que foi aprovado o fechamento do Congresso, sem prazo para reabertura. Os jornais foram invadidos e postos sob o controle de censores militares. O governo passou a intervir diretamente em estados municípios e seus efeitos não se sujeitavam à apreciação judicial (BARROS, 1998).

\section{RELAÇÕES PÚBLICAS NAS DÉCADAS DE 1960 E 1970}

A profissão de Relações Públicas foi regulamentada no Brasil na década de 1960. O primeiro curso de Relações Públicas, nos moldes de gradua- 
ção, foi instituído em 1967, na cidade de São Paulo, na Escola de Comunicações e Artes da USP (Universidade de São Paulo), relata Freitas (2009).

Torquato (2002) destaca que na década de 1970 a luta de classes invadia até o território da comunicação, onde os profissionais das diferentes habilitações competiam entre si por colocações no mercado.

Não se aceitava facilmente que alguém da academia pudesse emprestar seus esforços à área privada... Parceria, integração e trabalho comum eram verbetes sem direito a ingressar nas páginas da negociação coletiva. Os manuais dos trabalhadores e os dos empresários exibiam alfabetos diferentes. Tratava-se, portanto, de um desafio inimaginável, quase um suicídio, alguém da área acadêmica optar por um exercício reflexivo na área empresarial (TORQUATO, 2002, p. 04).

Na época, graduandos e acadêmicos de Relações Públicas eram alvo de acusações de ligação e de serem um resultado do regime ditatorial, menciona Freitas (2009). Essa situação dificultava inclusive o acesso dos alunos do Departamento de Relações Públicas, Propaganda e Turismo ao Departamento de Jornalismo. A autora relata que contribuíam para a formação dessa visão as palestras promovidas pela ABRP para os estudantes de Relações Públicas nas quais apresentavam os excelentes trabalhos técnicos desenvolvidos pelos militares.

Com os passar dos anos, discutiu-se qual o melhor lugar entre as áreas de conhecimento para as Relações Públicas. Freitas (2009) aponta que no fim da década de 1970 manteve-se a definição de que a função diz respeito ao campo da comunicação social. Mesmo ainda que muitos defendam sua inserção no campo das ciências da administração, devido ao fato de que as Relações Públicas tinham a comunicação como um meio, e não como a finalidade da atividade. Esse tipo de polêmica foi superada quando as lideranças reconheceram a importância de cada função para as organizações e academia.

A respeito da atuação do profissional, destaca-se a seguir a sua atividade na área governamental, especialmente no período da ditadura militar.

"Quando cada indivíduo estiver inteiramente consciente de seu direito de discutir e opinar acerca dos problemas governamentais e puder contar com recursos para exercitar esse direito, as RRPP terão contribuído para assegurar o apoio público." (ANDRADE, 1993, p.49). Segundo o autor este deve ser o papel das Relações Públicas em um governo e no trato com a so- 
ciedade, porém esta forma de atuação estava longe de acontecer realmente devido ao regime militar instaurado no Brasil.

De acordo com Pinho (2008) ao traçar um paralelo com a visão tradicional das Relações Públicas, é possível perceber que o trabalho era muito fragmentado e periférico. Resumia-se nas relações com a imprensa e nas relações com o governo, como se apenas isso bastasse. Cuidava-se de detaIhes: como divulgar, fazer imagem e, principalmente, organizar cerimoniais e eventos. Na verdade, as Relações Públicas possuem natureza e função política. Foram graças aos embates, choques, oposições e resistências, entre as diferentes classes sociais, que surgiu o despertar de operários, empresários e governo para o investimento em políticas e ações de comunicação. Estava, assim, firmado um ambiente propício e adequado para o nascimento da profissão de Relações Públicas.

No Brasil, as Relações Públicas surgem especialmente voltadas para a administração pública, amparada por decretos-lei que instituíam serviços de informação, divulgação e publicidade de vários órgãos públicos. A ditadura de Getúlio Vargas, na década de 40, por exemplo, tinha, em matéria de comunicação, o objetivo de elaborar e utilizar técnicas de persuasão, tendo em vista a perpetuação do poder; os esforços nessa área foram pautados pela demagogia e pela mera utilização da publicidade governamental, informa Pinho (2008).

O fato de a profissão no Brasil ter nascido dentro do regime militar, através da lei 5.377, foi marcante, pois seu exercício era controlado pelo governo.

Isso levou a atividade de Relações Públicas - essencialmente democrática - a se recolher e a se dedicar quase que exclusivamente às atividades internas das empresas, prática existente até hoje. As empresas temiam qualquer tipo de manifestação pública, e projeção de sua imagem; muitas passaram a contratar militares como seus porta-vozes, ficando os Relações Públicas sob suspeita de estarem a serviço da ditadura (FRANÇA, 2001).

Andrade (1993, p. 49) destaca dois fatores a favor das Relações Públicas governamentais, o primeiro deles é a informação: "um governo democrático precisa informar os seus governados. Isso não envolve, necessariamente, qualquer elemento de persuasão." O segundo fato é o argumento administrativo, explicado da seguinte maneira: "certas medidas administrativas não alcançarão sucesso, a menos que o público ou setores de público sejam 
adequadamente informados a respeito de seus deveres e direitos.".

O governo na busca de atender seus interesses, muitas vezes criou atividades e funções que poderiam ser confundidas com as Relações Públicas, devido ao seu caráter institucional e relação com o trato da imagem pública. Andrade (1993, p. 49) diz que por estes e outros motivos não é fácil estabelecer os limites de atuação das Relações Públicas governamentais e de outras profissões e "haverá sempre lugar para argumentos contrários ao emprego de Relações Públicas nas atividades do governo.".

Conforme Peruzzo (1986) foi no período da ditadura militar que as estruturas de comunicação do Brasil ganharam forma. No governo do Marechal Costa e Silva, havia muita preocupação com a aparência do governo, foi criada a AERP - Assessoria Especial de Relações Públicas da Presidência.

A duração da AERP foi curta, mas nessa fase foram criadas as bases do sistema de comunicação social do governo que permanece até hoje. $O$ grupo de trabalho se propunha a alcançar os seguintes objetivos:

- informar à nação brasileira a real situação do país; das intenções do futuro governo (Costa e Silva) e, sobretudo, de suas grandes metas;

- motivar a massa, conquistar e manter sua boa vontade e esperança, para o presidente eleito;

- esclarecer a opinião pública nacional, de preferência, procurando influir em sua ação e integrá-la com o futuro governo, visando à felicidade do Brasil;

- auxiliar na neutralização da ação subversiva e corruptora;

- cooperar na informação e esclarecimento da opinião pública internacional e formar uma imagem positiva do presidente eleito" (PERUZZO, 1986, p. 116). 
Porém, segundo Peruzzo (1986), a afirmação da profissão no governo militar só se deu durante o mandato de Emílio Garrastazu Médici, com a atuação do general Toledo de Camargo no cargo referente à comunicação. Nesta fase, o objetivo era aumentar a popularidade do presidente. $\mathrm{E}$ os seguintes níveis de temas eram desenvolvidos: primeiro a educação informal, com assuntos sobre saúde, higiene, técnicas de trabalho, com o objetivo de melhorar as condições de vida. Em seguida, o fortalecimento do nacionalismo, amor ao trabalho e patriotismo. E por fim, desenvolver no povo a esperança no crescimento do país.

Para Matos (1999), no período autoritário, com a criação da Assessoria Especial de Relações Públicas (AERP) no segundo governo militar, foi dada grande ênfase à atividade de Relações Públicas Governamental, inserida na constituição de uma imagem pública do governo. Essa ênfase deu-se dentro de uma visão de comunicação institucional que se diferenciou da propaganda política mais tradicional e conhecida até então. As Relações Públicas, no período da AERP, cumpriram a função de preenchimento do espaço da informação e comunicação suprimida pela censura então vigente, especialmente durante o governo Médici.

O coronel Octávio Costa, foi um dos mais bem preparados militares no campo da comunicação social e era responsável pelos trabalhos da AERP. A ele é atribuído, o sucesso da política de comunicação dos governos militares. "Foi ele que organizou os eixos dessa política, definindo os seguintes princípios: a legitimidade, a impessoalidade, a verdade, a integração, a eficiência e a liberdade de expressão," revela Torquato (2002, p.16).

Torquato (2002) relata que na década de 1960 havia muitas disputas profissionais entre os profissionais de Relações Públicas e os jornalistas, pois os jornalistas começaram a ocupar espaços nas organizações privadas que os profissionais de Relações Públicas consideravam seus. "A disputa interna, nas empresas, dava-se em torno da estrutura (imprensa ou Relações Públicas) responsável pelo comando da área da comunicação." (TORQUATO, 2002, p.02).

O presidente Costa e Silva teve muita preocupação com a imagem do governo e por isso, criou a AERP - Assessoria Especial de Relações Públicas. O trabalho de Relações Públicas neste governo começou com a formação de um Grupo de Trabalho de Relações Públicas quando Costa e Silva foi designado para substituir Castelo Branco na presidência da república, de acordo com Peruzzo (1986). Este grupo já existente se propunha a: 
a) fixação de temas que serão a base da ação do grupo, considerando-se tanto o próximo governo como o presidente e sua esposa;

b) levar ao presidente sugestões sobre seu comportamento até a posse;

c) estudo da conveniência das campanhas promocionais;

d) oferecimento de sugestões para aplicação no próximo governo de modo a conquistar a opinião pública;

e) divulgação e informação tanto sobre a pessoa do presidente como seus planos de governo;

f) estudo da estrutura, em nível presidencial de um órgão de RP para funcionar no próximo governo (PERUZZO, 1986, p.115).

Algum tempo após a posse do general Costa e Silva foi criada a AERP, como forma de concretização do item ' $f$ ' da proposta do grupo de trabalho de Relações Públicas. O primeiro a estar à frente da AERP foi o Coronel Ernani D’Aguiar. Peruzzo (1986) relata que os objetivos do grupo de trabalho extinto e da AERP seguiam o mesmo projeto. Neste período foram criadas as bases do sistema de comunicação social do governo. Bases estas que continuam sendo consideradas até hoje. O grupo de trabalho tinha como principal preocupação a imagem pessoal de Costa e Silva e fins políticos.

O trabalho de Relações Públicas no governo de Costa e Silva foi muito valorizado, porém a afirmação de sua importância no governo militar foi no mandato de Emílio Garrastazu Médici, relata Peruzzo (1986). O general Toledo de Camargo foi posto à frente da Assessoria de Relações Públicas e buscava aumentar a popularidade de Médici, uma das formas utilizadas, foi destacar suas idas aos campos de futebol ouvindo seu rádio de pilha como os demais cidadãos.

No período dos governos militares buscava-se a aproximação da população com o governo. Mesmo tendo imposto o regime militar, os governantes 
queriam "preservar as condições favoráveis à acumulação capitalista, utilizando todos os meios disponíveis para neutralizar a ação daqueles que não consentiam." (PERUZZO, 1986, p.118). Nesse contexto, as Relações Públicas eram utilizadas na busca de legitimação do regime perante a população, mesmo não atendendo a maioria de seus interesses e necessidades.

No processo de abertura política, Peruzzo (1986) defende que os processos de Relações Públicas foram muito utilizados para buscar o comprometimento das classes dominadas com os interesses da burguesia nacional e internacional.

O dia-a-dia das ações do governo está permeado pelas Relações Públicas, nos aspectos cerimoniais, notas oficiais, entrevistas coletivas ou declarações dos membros do governo através dos meios de comunicação de massa. O porta-voz do presidente, ao conceder entrevistas à imprensa está informando sobre temas de interesse da nação, o que tem grande valor para a sociedade. Porém, ele trabaIha e seleciona as informações, dá somente a versão que interessa ao governo sobre os fatos e , quando for o caso, procura tranqüilizara nação sobre temas polêmicos. Tudo isso são Relações Públicas. Do mesmo modo faz RRPP qualquer outro membro do governo. $\mathrm{E}$ isso é previsto pelas RRPP que, com a característica "onipresença”, sem encarregam de envolver todas as pessoas, no caso, que participam do governo, na política de RRPP (PERUZZO, 1896, p.121)

As diretrizes que deveriam ser seguidas pela AERP foram estabelecidas através do Decreto $n^{\circ} 63.516$, de 31 de outubro de 1968. Dentre estas regras, estavam as seguintes funções

divulgação dos planos governamentais, a realização de pesquisas e análises de opinião pública, o assessoramento dos órgãos do Executivo em seus pronunciamentos públicos, o entrosamento dos Serviços de Relações Públicas, a motivação dos públicos internos e a formação e consolidação do conceito do Brasil no exterior (ANDRADE, 2002, p.103).

A política das Relações Públicas do governo devia seguir o princípio da impessoalidade, para evitar promover partidos ou políticos específicos. O que implicava em ocultar e fazer com que os governantes se isentassem da responsabilidade nas aparências com o público e no cumprimento dos fins sociais. Andrade (2002) relata também que foi no governo de Médici que foi 
determinado que nenhuma obra pública deveria receber placas com o nome dos governantes responsáveis pelo feito.

A década de 1960, na evolução das Relações Públicas brasileiras, foi um período de preocupação com o exercício da atividade, destacaKunsch (2009). Segundo o autor, esta situação ocorria tanto no campo profissional quanto no acadêmico.

Foi nessa década, em 1968, que se regulamentou a profissão, mediante a Lei Federal $n^{\circ} 5.377$, que fora aprovada pelo Congresso Nacional no final de 1967. Com isso, a atividade se tornou privativa dos bacharéis de Comunicação Social com habilitação em Relações Públicas e que estivessem registrados em um dos oito conselhos regionais espalhados pelo país. A lei se centraliza nos objetivos da "profissão"; sua regulamentação foi comemorada com grande júbilo, ressaltando-se o pioneirismo mundial da iniciativa(KUNSCH, 2009, p.26).

A atuação agressiva da AERP acabou por influenciar as empresas, muitas das quais chegaram a ter militares na gestão das Relações Públicas, o que se mostraria bastante negativo para seu conceito, passando assim, a serem vistas como suspeitas e enganosas nos meios intelectuais, artísticos, sindicais e midiáticos, relata Kunsch (2009). Porém, no mesmo período, Kunsch (2009) cita que também ocorreram fatos que trouxeram reconhecimento para a profissão de Relações Públicas, mesmo que ainda voltadas para o exercício da profissão. Cândido Teobaldo de Souza Andrade lançou em 1962, "o primeiro livro brasileiro da área, Para entender Relações Públicas, que delinearia os contornos básicos de um incipiente corpus-doctrinaebrasileiro." (KUNSCH, 2009, p. 26). E, José Rolim Valença e José Carlos Fonseca organizaram em São Paulo, a Consultoria de Relações Públicas (AAB), uma grande escola de formação profissional e modelo para outras agências.

Dois fatos marcaram o desenvolvimento da comunicação pública durante os governos militares. Um deles, segundo Novelli(2009, p. 489),foia criação das diretrizes de Relações Públicas para o governo aprovadas em 1968 pelo general Costa e Silva, "tendo sido essa a primeira vez em que a atividade de Relações Públicas era citada como função política e aliada ao poder, além do jornalismo". O outro fato consiste na utilização do termo comunicação para abranger as áreas de jornalismo, Relações Públicas e propaganda, utilizado em 1970 pelo general Emílio Garrastazu Médici. “A comunicação foi utilizada por ele de forma estratégica em apoio à ideologia da segurança 
nacional, à ideia de reconstrução do país e à melhora do nível de vida da população." (NOVELLI, 2009, p. 489).

Já na década de 1970, "as relações entre comunicação e política foram estruturadas a partir de ação conjunta entre um sofisticado sistema de comunicação e de coerção consolidado a partir de estratégias militares com estética publicitária." (NOVELLI, 2009, p.489). Nesta época era a AERP o órgão responsável pela comunicação social do governo e tinha como titular, obrigatoriamente, um profissional de Relações Públicas, conforme descreve a autora.

Em termos práticos, a AERP tinha dois públicos principais: a população brasileira, considerada seu "público interno"; e a opinião pública internacional, compreendida como "público externo". Foi traçado um perfil do homem brasileiro e para ele eram dirigidas as campanhas que procuravam defender valores importantes para os militares, como força, disciplina, respeito à hierarquia, entre outros, uma vez que esses valores seriam imprescindíveis para o desenvolvimento dos cidadãos e do próprio país (NOVELLI, 2009, p.489).

Um dos exemplos de atuação da AERP que Novelli cita (2009) foi em relação à imagem do então presidente, o general Emílio Garrastasu Médici. Foi constatado que, no início de seu mandato, ele era pouco conhecido pelo povo. Para solucionar esta situação, foi criada uma estratégia para tornar mais visível a imagem e o discurso do presidente, de forma a torná-los compatíveis também com a proposta de comunicação já estabelecida.

Distribuíram-se fotos e discursos do presidente aos órgãos públicos, à imprensa e às instituições formadoras de opinião; veicularam-se filmetes clamando pela participação popular no desenvolvimento do país; editaram-se várias publicações contendo os artigos e discursos do presidente; as audiências presidenciais eram exaustivamente divulgadas, bem como suas viagens; e se observava um cuidado especial com a imprensa nacional e internacional, que recebia toda informação que o governo gostaria de ver publicada (NOVELLI, 2009, p.490).

No último governo militar, foi criada a Secretaria de Comunicação que tentava buscar novos caminhos para a comunicação governamental. Com amplos poderes, a Secretaria tinha como missão contornar o desgaste político do regime militar e preservar a imagem de seu titular, Figueiredo. (NOVELLI, 2009)

Muitos foram os decretos e leis sancionados relacionados à comunica- 
ção e às Relações Públicas no Brasil. Muitas mudanças foram criadas e revogadas no período de construção de funções e identidade da profissão. Apesar da repressão imposta, os congressos podiam ser realizados para discussões acadêmicas e definições que contribuíram para a elaboração dos estatutos que regem até hoje a profissão.

\section{RELAÇõES PÚBLICAS E DITADURA - IMPLICAÇõES E IMPRESSÕES}

Além dos dados bibliográficos e documentais, buscou-serelatos para captar percepções sobre as Relações Públicas, o papel da profissão no período do regime militar e para descobrir se há algum resquício deste período de governo na forma de atuação dos Relações Públicas ainda hoje.

A pesquisa realizada em livros, periódicos, reportagens da área da comunicação social, história do Brasil e da profissão de Relações Públicas, além da legislação brasileira vigente na época da ditadura militar permitiu algumas observações para traçarum paralelo entre o que ocorreu na época da regulamentação da profissão e a interferência desses fatos na construção do perfil do profissional de Relações Públicas atual. Porém, a entrevista ajudou a esclarecer algumas hipóteses, baseadas na diversidade de opiniões e riqueza dos comentários, visto que não havia pretensão de estabelecer conclusões precisas e definitivas sobre o tema.

A entrevista realizada foi do tipo fechada, realizada por meio de um questionário enviado por e-mail a pesquisadores da área da comunicação. O critério para escolha dos entrevistados foi o envolvimento acadêmico ou profissional com as Relações Públicas ou Comunicação Social no período da ditadura militar no Brasil ou com estudos relacionados à história da profissão de Relações Públicas.

O questionário enviado era composto por cinco perguntas abertas onde os entrevistados tiveram espaço para se posicionar a respeito do assunto abordado.Dos 14 questionários enviados, três foram respondidos, todos por pesquisadores da área de Relações Públicas os quais são denominados como pesquisadores A, B e C $C^{2}$. A seguir, são destacadas algumas opiniões dos entrevistados, as quais contribuíram para a formulação de novos questionamentos sobre o tema.

2 Respondente A: graduou-se em RP em 1979; Respondente B: graduou-se em RP em 1973; Respondente C: graduado em área afim à comunicação, especializou-se em RP em 1965. Todos possuem formação em nível de doutorado na área de comunicação, atuam na docência e desenvolvem estudos/publicações na área RP. 
Para a primeira pergunta, a qual questionava se o entrevistado acredita que o regime militar afetou a atuação do profissional de Relações Públicas naquela época, todos concordaram que sim, o governo militar brasileiro afetou a forma de atuação da profissão de Relações Públicas, muitas vezes, anulando-a. Acrescentam também que pouco pode desenvolver-se a profissão, pois o regime não era propício ao gerenciamento da comunicação, que era controlada pelo regime tanto nas organizações públicas, quanto nas privadas e era de apenas uma via. Conforme verifica-se em pesquisa bibliográfica, eram os coronéis e generais nomeados pelo governo que controlavam as assessorias de comunicação. O objetivo era transmitir as informações com vista apenas na aceitação da população, não era dado algum tipo de retorno ou informação. $O$ valor da transparência não era utilizado nesse caso das Relações Públicas.

A seguir, questionou-se ao entrevistado se acredita que o regime militar interveio na construção da identidade do profissional e/ou da profissão de Relações Públicas. As respostas foram divergentes se sim ou se não, porém as justificativas mostram que todos concordaram que a identidade dos Relações Públicas não pode ser construída plenamente, porque não foi possível discutir quais seriam suas funções e atividades, sem contar que as Relações Públicas não tinham muita representatividade na época. Neste ponto, o regime militar também é citado como entrave no desenvolvimento da profissão. $O$ entrevistado $C$ faz a seguinte colocação "Relações Públicas e comunicação organizacional não tinham forte representatividade na época. As primeiras entidades de comunicação tiveram início em 1967. O poder militar impediu a construção de qualquer identidade profissional das Relações Públicas e da comunicação".

Uma das perguntas pontuava: "Você acredita que o regime militar interferiu na construção da imagem do profissional e/ou da profissão de Relações Públicas perante a sociedade naquela época? Explique." Os pesquisadores foram unânimes em afirmar que a sociedade pode sim ter uma visão equivocada dos Relações Públicas, dois motivos foram citados, porém, ambos relacionados a posição que a função ocupava no regime militar. Os governantes se apropriaram das ferramentas de Relações Públicas para melhorar sua imagem e controlar as informações que chegavam à população. A relação com jornalistas também foi truncada. Por estar a serviço do governo, muitas vezes as ordens eram referentes à censura e trato ufanista da real situação em que o país se encontrava. Isto pode ter 
dado a entender para a sociedade que a profissão não tinha relações com o povo e a democracia, parecia estar apenas ligada ao regime militar. Conforme pesquisa bibliográfica realizada mostra, até mesmo outros profissionais da comunicação, mais especificamente os jornalistas, tinham restrições aos Relações Públicas. E como cita Torquato, entrar no meio organizacional privado era muito difícil devido às restrições do público com os profissionais.

Na questão seguinte "Se você respondeu a questão anterior de modo afirmativo, acredita que essa imagem, a qual sofreu afetações em decorrência da ditadura, persiste até hoje?" Para dois dos três entrevistados, esta situação mudou e hoje a profissão tem mais espaço para atuar nas organizações e o público pode ter uma imagem diferenciada de seu trabalho. É citada uma desvantagem nessa expansão, o fato de muitas organizações trocarem a nomenclatura da profissão para assistente ou analista de comunicação. Com opinião contrária, o entrevistado $C$ defende que em decorrência da ditadura militar os Relações Públicas se apropriaram apenas das funções operacionais, deixando de lado o lado estratégico e a atividade ainda não está realmente inserida no planejamento e organograma das organizações.

Perguntou-se ainda aos entrevistados a respeito de fontes de dados que apontem indícios sobre a interferência do regime militar na profissão de Relações Públicas. As diferentes fontes de consulta citadas mostram que o tema ainda não possui referências específicas e aprofundadas sobre o entendimento da história da atividade e sua relação com atual identidade profissional, caracterizando-se como um tema não amplamente explorado.

A partir das respostas dos entrevistados ao questionário elaborado percebe-se que há concordância em relação à interferência do regime militar no desenvolvimento da profissão de Relações Públicas no Brasil e que ainda existem resquícios dessa influência. Além disso, o fato de alguns os profissionais não se sentirem à vontade para opinar sobre este tema pode indicar a necessidade de estudos mais aprofundados e maior abertura nas discussões e pesquisas sobre o assunto.

\section{CONSIDERAÇÕES FINAIS}

Percebe-se que a atuação do profissional de Relações Públicas foi por muito tempo influenciada pelas ações do governo militar no caso do Brasil. Inclusive a sua imagem como profissional civil no período pouco se comenta, pois a maioria dos Relações Públicas citados eram militares membros do governo e que decidiam o que seria veiculado ou não, visando favorecer e 
melhorar a imagem dos governantes, principalmente no caso do presidente da república.

Esta forma de emprego das Relações Públicas pode ter deixado a profissão com uma visão deturpada de suas funções. Pouco atuante no meio organizacional, o que mais se viu foi a atuação no meio político, onde se tentava melhorar imagem e mostrar os benefícios do regime.

O primeiro modelo de comunicação entre governo e sociedade ocorreu durante a ditadura militar, onde a propaganda política direta foi substituída por um discurso indireto, ligado a padrões de comportamento e educação cívica, segundo Matos (1999). No processo de redemocratização, técnicas de marketing e lógica de mercado foram incorporadas às práticas de Relações Públicas.

Entende-se que o papel das Relações Públicas na comunicação governamental precisa ser repensado na sua função estratégica, para que se reconheça sua importância para o planejamento e estabelecimento de canais de comunicação entre governo e cidadãos.Cabe aos profissionais de Relações Públicas contemporâneos continuar o esforço para afirmar ao grande público o verdadeiro sentido e importância da sua atuação no mercado. Destacar suas funções, princípios e conduta ética veementemente defendida.

A pesquisa bibliográfica realizada mostrou que muitas das diretrizes que regem o campo das relações públicas vigoram desde a década de 1960. Porém, estes princípios têm estado mais em foco atualmente, quando os profissionais buscam reconhecimento e o espaço não conquistado nas organizações outrora.

Percebe-se que muito da imagem que se tem da profissão provém do papel que tinha na fase ditatorial, onde os comunicadores tinham o papel de cuidar da imagem dos governantes e torná-los mais próximos da população, além do trabalho de divulgação de mensagens a favor do regime, mostrar suas qualidades para que as revoltas pudessem ser contidas e ter a menor taxa de adesão possível. Devido a estas funções e o comando dos setores responsáveis pelas Relações Públicas governamentais estar nas mãos dos generais e coronéis militares, os comunicadores desta área acabaram por serem vistos como parte articuladora do regime, profissionais a serviço da ditadura militar. Como se observa nas entrevistas realizadas, esta visão prejudicou o desenvolvimento da profissão perante o mundo corporativo. Acredita-se que população não via com bons olhos os Relações Públicas e os colegas de profissão, como os jornalistas, viam-se em lados opostos ao profissional na luta pela democracia. 
A maior fonte para consulta de informações localizada sobre as Relações Públicas no período ditatorial foi a legislação da época. Muitos decretos, leis e atos institucionais regulamentaram diferentes fases e processos da profissão nesse período. Muitas alterações eram feitas, dificultando a consolidação da carreira, pois suas atribuições eram alteradas, proibidas e autorizadas em curtos períodos de tempo. As diferentes entidades responsáveis pela comunicação do governo que foram criadas e extinguidas em curtos períodos de tempo também são fatores que demonstram a dificuldade de se firmar um projeto único e sólido para o exercício das Relações Públicas.

A entrevista realizada com estudiosos da área da comunicação também confirmou que o assunto não foi plenamente discutido pela academia. Não há registros específicos para consulta e busca de informações precisas. O tema merece ser mais estudado, pois nota-se que há a percepção de que o regime militar teve influência sobre a profissão de Relações Públicas, assim como em todos os setores da sociedade.

O desenvolvimento da pesquisa permitiu articular algumas hipóteses para responder a questão que norteou o estudo, a saber: "Em que implicou a ditadura militar na atuação dos profissionais de Relações Públicas no período de regulamentação da atividade? Essas implicações estão presentes ainda hoje?":

- Diferentemente dos jornalistas, pouco se ouviu falar da atuação dos profissionais de Relações Públicas em defesa da liberdade de expressão, ética e transparência, pois os Relações Públicas não atuavam como articuladores, no papel de gestor da comunicação.

- O profissional de Relações Públicas assumiu uma postura de porta voz ao atuar apenas para repassar informações referentes às organizações e governo, além de assumir demais papéis secundários relacionados à comunicação. Sua imagem perante à população brasileira pode ter sido interpretada de forma errônea não sendo entendidas todas as funções da profissão de Relações Públicas.

- Por não poder executar plenamente suas atividades devido às restrições impostas pelo regime militar, a profissão de Relações Públicas tornouse de necessidade secundária nas organizações atuais na visão dos gestores.

Compreende-se que essas são hipóteses que podem nortear pesquisas futuras. De acordo com as palavras de Andrade (1993) é necessário trabalho constante para a plena aceitação e compreensão da profissão de Relações Públicas no Brasil, tanto no âmbito das organizações governamentais, quanto nas instituições privadas. Assim, entende-se que o estudo do processo 
histórico da profissão na sua relação com a história do país constitui uma área de estudos a ser mais explorada e que pode contribuir para o debate sobre o papel das Relações Públicas nos dias de hoje.

\section{REFERÊNCIAS}

ALVERENGA, Maria Amália de Figueiredo Pereira e ROSA, Maria Virgínia de Figueiredo Pereira do Couto. Apontamentos de metodologia para a ciência e técnicas de redação científica. Porto Alegre: Sergio Antônio Fabris Editor, 1999.

ANDRADE, Cândido Teobaldo de Souza. Para entender Relações Públicas. São Paulo: Edições Loyola, 1993.

. Curso de Relações Públicas. São Paulo: Atlas, 2002.

BARROS, Edgard Luiz de. Os governos militares. São Paulo: Contexto, 1998.

CALADO, Carlos. Tropicália: o avesso da bossa nova. InDE CARLI, Ana MerySehbe; RAMOS, Flávia Brocchetto (Orgs.). Tropicália: gêneros, identidades, repertórios e linguagens. Caxias do Sul: EDUCS, 2008.

COUTO, Ronaldo Costa. Memória viva do regime militar. Brasil: 1964-1985. Rio de Janeiro: Record, 1999.

. História indiscreta da ditadura e da abertura. Rio de Janeiro: Record, 2003.

DUARTE, Jorge. Entrevista em profundidade. In DUARTE, Jorge e BARROS, Antônio (Orgs.). Métodos e técnicas de pesquisa em comunicação. São Paulo: Atlas, 2005.

FRANÇA, Fábio $O$ conceito do profissional de Relações Públicas no mercado. 2001. Disponível em <www2.metodista.br/agenciarp/>. Acesso em 05 de maio de 2011.

FREITAS, Sidinéia Gomes. As entidades de classe de Relações Públicas no Brasil: caminhos e descaminhos. In KUNSCH, Margarida Krohling (Org.). Relações Públicas: história, teorias e estratégias nas organizações contemporâneas. São Paulo: Saraiva, 2009.

KUNSCH, Waldemar Luiz. Gênese e desenvolvimento do campo profissional e acadêmico das Relações Públicas no Brasil. In KUNSCH, Margarida Krohling (Org.). Relações Públicas: história, teorias e estratégias nas organizações contemporâneas. São Paulo: Saraiva, 2009.

MARCONI, Marina de Andrade e LAKATOS, Eva Maria. Técnicas de pesquisa. São Paulo: Editora Atlas, 1985.

MATOS, Heloiza. Das Relações Públicas ao marketing público:(des)caminhos da comunicação governamental. Originalmente publicado em CORRÊA, Tupã Gomes, FREITAS, Sidinéia Gomes (Org.). Comunicação, marketing, cultura: sentidos da administração do trabalho e do consumo. São Paulo: ECA/USP; CLC, 1999. p. 58-66. Disponível em http:// www.portal-rp.com.br/bibliotecavirtual/projetosdepesquisa01/0078.htm. Acesso em: 15 de setembro de 2011.

NOVELLI, Ana Lúcia Romero. Relações Públicas governamentais. In KUNSCH, Margarida Krohling (Org.).Relações Públicas: história, teorias e estratégias nas organizações con- 
temporâneas. São Paulo: Saraiva, 2009.

OLIVEIRA, Silvio Luiz de. Tratado de Metodologia Científica - Projetos de Pesquisas, TGI, TCC, Monografias, Dissertações e Teses. São Paulo: Pioneira Thomson Learning, 2002.

PERUZZO, CiciliaKrohling. Relações Públicas no modo de produção capitalista. São

Paulo: Summus Editorial, 1986.

PINHO, Julio Afonso. $O$ contexto histórico do nascimento das Relações Públicas. InMOURA. Cláudia Peixoto de. História das Relações Públicas:

Fragmentos da Memória de uma Área. Porto Alegre: EDIPUCRS, 2008.

TORQUATO, Gaudêncio. Tratado de Comunicação organizacional e política. São Paulo: Pioneira Thomson Learning, 2002.

VERGARA, Sylvia Constant. Métodos de pesquisa em administração. São Paulo: Editora Atlas, 2005.

\section{Daiane Scheid}

Doutoranda e mestre pelo Programa de Pós-Graduação em Comunicação da Universidade Federal de Santa Maria. Graduada em Relações Públicas. Atuou como docente na Universidade de Caxias do Sul e atualmente exerce a função de professora assistente no Curso de Comunicação Social - Relações Públicas com ênfase em Multimídia da Universidade Federal de Santa Maria - Frederico Westphalen.

\section{Taíla Lopes Quadros}

Graduada em Relações Públicas pela Universidade de Caxias do Sul. 